\title{
LAS COFRADÍAS MEDIEVALES EN EL REINO DE VALENCIA (1329-1458) ${ }^{1}$
}

\author{
Manuel BENÍTEZ BOLORINOS
}

Universidad de Alicante

Aunque el estudio de las cofradías valencianas del medioevo no debe reducirse al análisis de sus ordenanzas - pues éstas aparecen como respuestas concretas a las necesidades de tales corporaciones en un momento dado de su evolución- dicho análisis nos permite obtener un amplio conocimiento tanto de su aparición como de su posterior desarrollo.

Por este motivo, el presente trabajo tiene como objeto el estudio de las ordenanzas otorgadas por la Corona de Aragón a las cofradías del reino de Valencia, centrándose en el espacio temporal comprendido entre los reinados de Alfonso IV y Alfonso $V$. A pesar de la importancia del tema, los únicos estudios generales realizados hasta ahora han sido los de Tramoyeres Blasco y los de Paulino Iradiel. Para este nuevo enfoque se ha utilizado la abundante documentación existente en los registros de Cancillería del Archivo de la Corona de Aragón.

Las cofradías valencianas han sido definidas como asociaciones solidarias formadas por gentes con intereses en una misma profesión, devoción o identidad familiar que se aglutinaban en torno a un ideal religioso de hermandad. En una primera etapa sus fines fueron específicamente religiosos; a partir de 1283, Pedro III les otorgó la posibilidad de elegir representantes que se encargaran de la organización y administración de los oficios, mientras que desde mitad del siglo XIV las Cortes y las provisio-

1 El presente artículo ofrece una síntesis de la memoria de licenciatura defendida el día 21 de junio de 1997 en la Universidad de Alicante ante un tribunal conformado por don José Hinojosa Montalvo, don Juan Antonio Barrio Barrio y don Agustín Bermúdez Aznar. 
nes reales comenzaron a aprobar las cofradías existentes y otras nuevas ${ }^{2}$. Por lo tanto, la naturaleza de estas asociaciones se nos presenta como doble.

Por un lado, el surgimiento de esta forma de asociacionismo en el reino de Valencia está relacionado con la predicación efectuada por las nuevas órdenes religiosas que surgieron en Europa a partir del siglo XIl y que lograron llegar más allá de lo que hasta entonces había permitido el pequeño marco evangelizador de la parroquia; estas ordenes de reciente creación difundieron una religiosidad más conectada con la caridad y la devoción cristiana que con una espiritualidad de corte ascético ${ }^{3}$.

Por otro lado, las cofradías valencianas aparecieron, al mismo tiempo, en el marco del mundo artesano bajomedieval y, por lo tanto, surgieron como asociaciones dedicadas a la defensa de los intereses de los miembros de un oficio, logrando el reconocimiento jurídico-administrativo del $\mathrm{mismo}^{4}$. De este modo nos encontramos con dos tipos de cofradías que presentaban grandes semejanzas, pero que, al mismo tiempo, contaban con aspectos distintivos. Se trata de las cofradías religiosas y de las cofradías de oficio. Bonnassie habla de cofradías extraprofesionales, sencillas - formada por un sólo oficio-y de federación de oficios ${ }^{5}$.

Las cofradías religiosas o extraprofesionales surgieron como respuesta a las necesidades espirituales y devocionales de la sociedad bajomedieval. Se presentaban bajo la advocación de algún santo, de la Virgen o bajo algún otro signo religioso. Sus ordenanzas se dividian en tres aspectos: el organizativo (admisión de cofrades, elección de mayorales, pago de cuotas...); el religioso (el culto a la advocación); y el asistencial (cuidado de enfermos, protección de los cofrades empobrecidos; rescate de cautivos...). Como consecuencia del fervor religioso que las impulsaba tan sólo se admitían a aquellas personas que cumplían una serie de requisitos morales y llevaban una vida cristiana.

Por su parte, las cofradias de oficio añadían a todos estos elementos organizativos, religiosos y asistenciales, el hecho de estar formadas por miembros de un oficio concreto - de carácter sencillo, siguiendo la clasificación de Bonnassie-, o por varios oficios - aunque tanto en unas como en otras se permitía el acceso de sus familiares o de personas ajenas al oficio. De este modo, las cofradías de oficio si bien «no gozan de reconocimiento institucional, ni foral como los oficios, si tienen, en cambio, una estructura administrativa y una responsabilidad jurídica, pública y privada» ${ }^{6}$. Algunas de estas cofradías, desde finales del siglo XIV, lograron añadir ordenanzas de tipo

2 VV. AA. Oficios artesanales y comercio en Castellón de la Plana, Castellón de la Plana, 1993, p. 153.

3 M. LLOP CATALÀ, «La predicación y las Cofradías Valencianas, ss. XIV-XV». Boletín de la Sociedad Castellonense de Cultura, LVIII, 1982, pp. 11-16.

4 Paulino IRADIEL, "Corporaciones de oficio, acción política y sociedad civil en Valencia», Cofradías, gremios y solidaridades en la Europa Medieval, Estella, 1992, p. 263.

5 P. BONNASSIE, La organización del trabajo en Barcelona a fines del siglo XV, Barcelona, 1975, p. 32 .

6 Paulino IRADIEL, “Corporaciones de oficio, acción política...», p. 261. 


\begin{tabular}{|c|c|c|c|}
\hline 1.- Çabaters & Santa Lucía & Fusters & Juponers y vanovers \\
\hline Aluder i pergaminers. & Pellers. & Corders. & San Cristobal y San Amador. \\
\hline Santa Catalina. & Macips peraires. & Esparters. & 2. - Vera Creu. \\
\hline Cechs. & Peraires. & Laurados del Quart de Campanar. & San Migue. \\
\hline Sastres. & Camicers. & Pescadors. & Santa Trinidad. \\
\hline Corregerers. & Bracers. & Moliners. & 3.- Santa María. \\
\hline Pellicers. & Taberners. & Flequers. & San Pedio. \\
\hline Mercaders de Girona. & Corterdors d'orella. & Macips del pes real. & 4. - Santa María de Yessa. \\
\hline San Pedro. & Lauradors apellats del camino de Morvedre. & Forners. & San Juan de Yessa. \\
\hline Santa María. & Argenters. & Barbers. & 5.- Santa Naría. \\
\hline Ballesters de la ploma. & Lauradors de San Lázaro del camino de Monvedre. & Piquers. & San Agustin. \\
\hline San Vicente. & Lauradors jovers. & Bossers i carders. & 6.- San Guillem. \\
\hline San Miguel del lugar de Quart. & Calafiats. & San Antonio. & Santa María. \\
\hline Santa María del lugar de Quarti & Tapiners. & Tinters del drap de la lana. & 7.- Corazón de Cristo \\
\hline Maestres texidors. & Joves cabeteis i custiners. & Lauradors del lugar de Ruzáá. & San Antonio. \\
\hline Macips texidors. & Armers. & Bastexes del grao. & 8, - Sañ Jaime. \\
\hline Maestres i macips texidors. & Coliellers i bainers. & Ligadors de bales. Mestres d'obra de vila. & $\begin{array}{l}\text { San Antonio. } \\
\text { 9.- San Nicolás. } \\
\text { 10.-Santa Mlaria. } \\
\text { 11.-Cofradías de Morella. }\end{array}$ \\
\hline
\end{tabular}

laboral que les permitieron llevar a cabo un mayor control sobre los oficios que practicaban sus miembros, aunque se seguirá observando una clara disociación entre cofradía y oficio que tiende a reducirse al acercarnos a la Edad Moderna ${ }^{7}$. Por lo tanto, en el periodo analizado, se observa una evolución, en cuanto a las cofradías de oficios, que pasaron de ser meros reflejos de unas inquietudes religiosas, a ejercer un control, cada vez más importante, sobre los oficios. Pero la diferencia entre“ las cofradías medievales y los gremios de la Edad Moderna se encuentra en que las cofradías no centraron sus reglamentaciones en cuestiones técnicas y profesionales ${ }^{8}$.

Para acercarnos al estudio del fenómeno confraternal valenciano, el presente análisis ha sido dividido en tres partes. En la primera se estudiarán las motivaciones expuestas por los cofrades en las solicitudes de aprobación de las ordenanzas y los resquicios legales que permitieron la formación de estas asociaciones. En segundo lugar, se abordará el tema de los distintos tipos de cofradías - religiosas, de oficio, de conversos,... Y por último, se realizará un análisis general de los capítulos de las ordenanzas, atendiendo a los cuatro aspectos que se han ido mencionando: capítulos organizativos, capítulos religiosos, capítulos asistenciales y capítulos de carácter gremial.

7 V. AA. Oficios artesanales y comercio..., p. 154.

8 Ibidem. 
Hemos analizado para ello 73 cofradías y 93 privilegios entre los que podemos observar un predominio de las cofradías de la ciudad de Valencia (más del 75\%). Además, de las 73 cofradías, 35 pertenecían a cofradías de oficio, 27 a cofradías religiosas, 7 pertenecían a cofradías de labradores, una a la cofradía de ciegos, una a la de ballesters de la ploma de Valencia, una a la cofradía de macips del pes real y otra a la de mercaderes de Girona en Valencia.

\section{LAS MOTIVACIONES}

Las motivaciones o fines de las cofradías para formar hermandad aparecían expuestos en los documentos como justificaciones para lograr el privilegio real. En este sentido hay que tener en cuenta, además, los motivos expuestos por el monarca para otorgar dichas ordenanzas y que solían coincidir, en la mayoría de los casos, con los argumentados por las cofradías. Es decir, tanto las cofradías religiosas como las de oficio se presentaban, en su mayoría, como organizaciones religiosas y benéficas centradas en el culto, la caridad, la ayuda a cautivos y enfermos, el entierro de cofrades, etc. Bajo este signo, los cofrades solicitaron a lo largo del periodo estudiado la confirmación de tales asociaciones, la aprobación de nuevas ordenanzas o la recuperación de antiguos privilegios. Pero junto a periodos de aceptación, las cofradías sufrieron también prohibiciones concretas para su desarrollo.

\subsection{Las prohibiciones de la corona}

El movimiento confraternal valenciano se caracterizó desde un primer momento por la actitud cambiante de los monarcas que llevó a periodos de prohibición y periodos de aceptación de estas asociaciones. En este sentido se observan dos etapas separados por tales prohibiciones, puesto que la mayoría de estas asociaciones, con la única excepción de la cofradía de San Jaime, fueron suprimidas hasta que en el año 1329 Alfonso IV aprobó nuevamente los capítulos de la cofradía de çabaters anulando las disposiciones anteriores, coincidiendo con las Cortes celebradas en Valencia por el monarca aragonés.

Como afirma Paulino Iradiel, estas prohibiciones coincidían de forma generalizada con las producidas en Europa occidental en el mismo periodo. La causa parece residir en la lucha por el control del gobierno municipal que enfrentó a una menestralía ascendente contra la nobleza y la alta burguesía. La decisión restrictiva de los monarcas aragoneses hacia las corporaciones de artesanos podría devenir de un pacto entre el poder aristocrático y el monárquico. Pero en las Cortes del año 1329 tales prohibiciones fueron derogadas como consecuencia de la mayor participación de los artesanos en la vida municipal valenciana debido al aumento demográfico y al desarrollo de los oficios artesanales de la ciudad ${ }^{9}$. Las reticencias del monarca para permitir la existencia de las cofradías se basaban también en que éstas se encontraban en el origen de

9 Paulino IRADIEL, “Corporaciones de oficio, acción política...», pp. 266-268. 
posibles tumultos y conflictos. Entre 1347 y 1349, años de la guerra de la Unión, se observa un nuevo periodo de restricciones por la participación de las cofradías en los conflictos $^{10}$.

\subsection{Los privilegios otorgados por Juan I}

Un hecho destaca en las ordenanzas concedidas por el monarca aragonés Juan I entre los años 1392 y 1393 . En tal fecha nos encontramos con el mayor número de privilegios otorgados a las cofradías valencianas (un total de 51 privilegios). Son años en los que el monarca se encontraba en la ciudad de Valencia tratando de fletar una expedición contra los rebeldes de Cerdeña y que resultó al cabo un completo fracaso al no lograr su objetivo de hacerse a la mar. De las 55 cofradías beneficiadas por las concesiones reales 51 de ellas (más del $90 \%$ ) se vieron obligadas a pagar una cantidad aleatoria de dinero a cambio de la aprobación y expedición de sus ordenanzas.

Como hipótesis de trabajo podría interpretarse que las necesidades monetarias de la Corona obligaron al monarca a conceder tales privilegios a cambio del pago de una tasa que aliviara el estado de las arcas reales y que las cofradías valencianas aprovecharon tal situación para imponerse una reglamentación que regulara sus actividades al tiempo que permitiera la legalización de su existencia. Las cantidades fluctuaron entre los 10 florines de oro de la cofradía de maestres peraires de Valencia y los 100 florines de oro pagados por los lauradors apellats del camí de Morvedre de Valencia

\section{LOS TIPOS DE COFRADÍAS}

Aparte de las cofradías religiosas y de las cofradías de oficios anteriormente mencionadas, en el reino de Valencia aparecieron otros tipos de hermandades de carácter más minoritario. Por cofradías religiosas hemos entendido aquellas que surgieron ante las necesidades espirituales y devocionales de la sociedad bajomedieval. En cuanto a las cofradías de oficios, el desarrollo del mundo artesanal supuso la diversificación de los oficios y, por lo tanto, la proliferación de las cofradías de oficio. Las diferencias entre éstas y las religiosas se nos muestran casi nulas a través del estudio de las ordenanzas. Los capítulos de unas y de otras se caracterizaban por un predominio de aquéllos que se centraban en la organización interna de la cofradía y en sus aspectos religiosos, en especial todos los relacionados con el ritual de la muerte, pero también con sus aspectos benéficos. Sin embargo, el objetivo fundamental de las cofradías de oficio no era la aspiración espiritual y asistencial de las religiosas, sino lograr una vía para organizar los oficios.

Por otro lado nos hemos encontrado con dos cofradías de conversos que se unieron en una sola hermandad en el año 1420. Se trata de las cofradías de San Cristóbal y San Amador. La cofradía de San Cristóbal estaba formada por la oligarquía de los conversos: médicos, plateros, especieros y mercaderes, mientras que en la de San

10 Paulino IRADIEL, “Corporaciones de oficio, acción política...», pp. 268-269. 
Amador se integraban sastres y juboneros ${ }^{11}$. La existencia de dos cofradías es un ejemplo de «... la ruptura de las estructuras sociales de la época judía y su adaptación a modelos cristianos, aunque no se puede hablar de un tipo de familia conversa característico... ${ }^{12}$. Según Luz Company hay que tener en cuenta dos tipologías familiares: la familia centralizada de las élites, integradas en la burguesía ciudadana, y la familia nuclear de menestrales y mercaderes que reafirmaron sus lazos a través de estas dos cofradías $^{13}$.

En el año 1420 se produce la unión de dichas hermandades. La causa de la unificación estribaba, según las ordenanzas, en una serie de debates, pleitos y divisiones que habían aparecido entre las dos. Por estos pleitos el monarca decidió revocar los privilegios concedidos anteriormente. Ante tal situación los mayorales y cofrades de ambas cofradías, movidos por la ausencia de obras caritativas, solicitaron en el año 1420 que fuera retirada la prohibición. Alfonso $\mathrm{V}$ concedió varios capítulos a la cofradía de conversos de San Cristóbal a la que se unieron los antiguos cofrades de San Amador, que desapareció como hermandad.

Por otro lado nos encontramos con la cofradía o collegi dels cent ballesters de la ploma. No era una cofradía de oficio sino un cofradía formada por artesanos de distintos oficios que se encargaban de la guardia urbana a las órdenes del sindich del consell de la ciudad de Valencia cuando se encontraban intramuros y del lochtinent general o del gobernador cuando se hallaban fuera de los muros. Su nombre derivaba del arma que portaban, la ballesta, y de la pluma que se colocaban en el sombrero como rasgo distintivo. Entre sus privilegios se hallaba el derecho a portar armas. Su labor se centraba en la guardia y servicio de la ciudad y en custodiar la senyera real siempre que hubiera que salir con el ejército en armas. Su residencia confraternal se encontraba en la capilla de San Jorge, bajo cuya advocación se hallaba la hermandad ${ }^{14}$.

Por último nos hemos encontrado con una cofradía formada por los ciegos de la ciudad de Valencia fue una de las que mayor número de ordenanzas obtuvo en forma de privilegios a lo largo del periodo estudiado. Hasta cuatro documentos, fechados en los años 1329, 1353, 1392 y 1407, recibieron por parte de los monarcas aragoneses. Entre sus capítulos sobresalían los elementos asistenciales tanto a los pobres que no pertenecian a la hermandad -que recibían cinco dineros en la fiesta de San Martín-, como a los propios cofrades, pues si alguno de ellos encontraba enfermo a algún compañero fuera de la ciudad debía darle la mitad de las almoinas recibidas durante ocho días; si al cabo de esos días el cofrade moría, debía encargarse de su entierro.

11 J. HINOJOSA MONTALVO, "Conversos y judaizantes en Valencia a fines de la Edad Media." Anales Valentinos, Año 1996, ํo 44. Valencia, p. 259.

12 J. HINOJOSA MONTALVO, “Conversos y judaizantes en Valencia...”, p. 258.

13 José Luis LUZ COMPANY, Evolución y estrategias de las familias judeo-conversas valencianas en el tránsito del siglo XV, Facultad de Geografia y Història, Valencia, 1993. Visto en J. HINOJOSA MONTALVO, "Conversos y judaizantes en Valencia...", p. 259.

14 J. HINOJOSA MONTALVO, "LoS contrastes de siglo S. XIV (1327-1410)", Nuestra Historia, Vol. III, Valencia, 1980, p. 114. 


\section{LAS ORDENANZAS}

\subsection{Capítulos organizativos}

\subsubsection{Condiciones de entrada}

Los capitulos que hacian referencia a las condiciones de entrada en las cofradías eran variados. En primer lugar hay que tener en cuenta que las cofradías se presentaban como asociaciones abiertas, es decir, aptas para gentes de cualquier estamento, ya fueran hombres o mujeres. Pero, a pesar de su apariencia de asociaciones abiertas, entre éstas ordenanzas aparecían algunos requisitos que iban limitando el acceso a dichas hermandades. En la cofradía de la Vera Creu de Xàtiva (1381), no se admitía a ninguna persona que estuviera en cualquier otra cofradía. Además, sólo los habitantes de Xàtiva y de su término podían ser cofrades. Si alguno abandonaba la villa con su mujer ya no podía ser tenido como cofrade y su lugar era ocupado por cualquier otro para que el número de miembros no disminuyera; si después de un tiempo el cofrade ausente volvía a Xàtiva podía considerarse nuevamente miembro de la cofradía antes que cualquier otro que esperase su turno, siempre que hubiese notificado al prior y a los mayordomos que su marcha no era para más de medio año. En un sentido parecido la cofradía de ligadors de bales de Valencia (1402), sólo permitía el acceso a los casados que residieran en la ciudad de Valencia y si algún cofrade se iba de la ciudad debía ser expulsado. En la cofradía de San Antonio de Valencia (1393) si alguno pertenecía a otra hermandad «...que aquella deu primer será puxa seruir la primera almoyna sens raptiu d'aquesta e que sen puxa scusar ab les majorals ... ${ }^{15}$. En los casos de cofradías de oficios se permitía el acceso a todos aquellos que realizaban tal oficio, pero también a quienes no lo practicaban

Las cofradías daban una imagen de apertura social hacia gentes de cualquier condición o estamento - con la excepción de aquellas cofradías de oficio que poseían una serie de elementos gremiales más acentuados. Pero en realidad estas asociaciones eran esencialmente de carácter restrictivo, ya que en ellas aparecían una serie de condiciones eliminatorias de carácter tanto pecuniario, como moral y religioso.

A pesar de su apariencia abierta, las cofradías realizaban una primera criba al imponer una suma de dinero a cuantos quisieran entrar en ellas. Si bien tales cantidades no eran por lo general excesivas, suponían un freno para cuantos marginados sociales vivían en las villas y ciudades valencianas y que disfrutaban de la existencia y desarrollo de estas hermandades sólo a través de la caridad ${ }^{16}$. En este punto hay

15 ACA, C, 1902, fol. 172r.

16 Aquí se incluirían las masas de inmigrados a la ciudad de Valencia, de los que tan sólo unos pocos llegaban a integrarse en la jerárquica estructura gremial, lo cual suponía a su vez la integración en la sociedad valenciana bajomedieval. El resto debían dedicarse a la mendicidad, al juego y a la prostitución, y por lo tanto se alejarían de comportamiento moral y espiritual exigido a los cofrades. R. NARBONA VIZCAÍNO, Pueblo, poder y sexo. Valencia medieval (1306-1420), Valencia, 1992, p. 39. 
que tener en cuenta que la cofradías eran un modo de integración en la sociedad cristiana bajomedieval junto con el oficio y la parroquia, y que los requisitos pecuniarios de entrada iban acompañados, las más de las veces, con una serie de condicionantes religiosas, pues únicamente los cristianos tenían acceso a dichas almoinas ${ }^{17}$; y otras de comportamiento ético, relacionadas con la predicación de las órdenes religiosas (franciscanos, dominicos y agustinos).

El segundo requisito de entrada a las cofradías era, por tanto, una mezcla de imposiciones morales y religiosas. Los mayorales de cada cofradía, o en su caso algunos prohombres, debían certificar si los aspirantes eran de buena fama, vida, condición y conversación, y en algunas que fueran también de buen estamento. En las ordenanzas otorgadas a la cofradía de San Pedro de Valencia en el año 1370 se especificaba que los mayorales debían certificar la fama del solicitante en el vecindario, y que no debía ser recibido nadie que tuviera fama de ladrón, homicida, adultero, jugador, adivino, usurero, que fuera soltero, alcahuete, que jugara a escondidas, que acudiera a las tabernas o que se embriagara públicamente. Las prohibiciones de carácter sexual recaían habitualmente sobre asuntos como el adulterio, vivir en concubinato o ejercer la prostitución, pues no sólo eran actos pecaminosos en sí e impropios de cristianos, sino que también podían dar pie a crímenes mayores como en el caso del juego ${ }^{18}$. Los aspirantes debían comportarse como fieles cristianos. Además, estas asociaciones estaban vedadas a los miembros de las minorías religiosas, no sólo por la propia naturaleza de la cofradía, su espiritualidad y sus ritos, sino también por prohibiciones concretas más o menos explícitas.

Aparte de las trabas ya indicadas para el ingreso en las cofradías, hay que tener en cuenta que la mayor parte de ellas limitaban el numero de sus integrantes en las ordenanzas.

\subsubsection{La organización administrativa}

El núcleo de la organización administrativa de las cofradías era el capítulo. Se trataba de un gobierno colegiado en el que sobresalían una serie de cargos específicos. Entre ellos destacaba en primer lugar el prior, un cargo religioso, y los mayorales, cuyas funciones eran bastante amplias: formar los turnos para velar a los enfermos, evitar disputas entre los cofrades, cobrar cuotas y multas, etc. Para ayudarles en su labor se hallaban los consejeros, mientras que los andadores eran empleados de la cofradía dedicados a avisar a los cofrades para las reuniones del capítulo, sepulturas, aniversarios y otros menesteres que dependían de cada cofradía.

Junto al prior, el principal cargo de la cofradía era el de mayoral, mayordomo, administrador o regidor. En su elección nos encontramos pocas diferencias entre las

17 En la documentación, este término aparece como sinónimo de cofradía.

18 Según Narbona Vizcaíno el juego estaba tan condenado moralmente como era practicado, pero en escasas ocasiones era castigado por la autoridad pública. R. NARBONA VIZCAÍNO, Malhechores, violencia y justicia ciudadana en la Valencia bajomedieval. 1360-1399, Valencia, 1990, p. 62. 
cofradías estudiadas. La duración de sus cargos era de un año en todos los casos, aunque también se podía hacer una nueva elección cuando alguno de los mayorales moría. En la cofradía de maestres i macips texidors (1440) además de limitar temporalmente su mandato se impedía que pudieran ser elegidos en los cuatro años siguientes. El número de mayorales solía variar entre dos y cuatro.

En cuanto a la forma de elegir tales cargos, podían utilizar dos modalidades. La mayoría de la cofradías se decantaban por un sistema democrático en el que los cofrades se reunían en capítulo y participaban en la elección de los regidores pudiendo ser elegidos los nuevos mayorales de entre todos los presentes. En el caso de la cofradía de macips del pes real (1392) se especificaba además que los mayorales elegidos debían ser macips practicantes de tal oficio. En algunas cofradías podían intervenir en la elección los mayorales del año anterior, aparte de los cofrades. La segunda era más restrictiva que las anteriores pues la elección se encargaba a los mayorales salientes junto con otros cargos específicos de la cofradía. Esta forma de elección permitía el control de la cofradía por parte de unos pocos.

De este modo nos encontramos con el sistema democrático y el sistema cerrado que Bonnassie menciona para los gremios barceloneses. El primero se utilizaba en gremios pequeños y era fuente de desórdenes; el segundo, tan antiguo como el anterior, se aplicaba a los gremios más numerosos con algunas excepciones ${ }^{19}$. El origen de este último parece estar relacionado con el sistema de cooptación indirecta que se utilizaba para elegir a los cargos municipales. Se trataba de un sistema en el que los cargos salientes nombraban a los electores y éstos a su vez a los candidatos a través de las parroquias ${ }^{20}$. En ninguna de las cofradías estudiadas se ha detectado la elección a suertes que apareció en los gremios barceloneses a partir del año 1474 como un compromiso entre los modelos anteriores ${ }^{21}$.

Al terminar el tiempo de duración de tales cargos, los mayorales debían presentar las cuentas de las pecunias pagadas por los cofrades a lo largo de dicho periodo. El motivo de esta rendición de cuentas era doble. En primer lugar controlar los gastos que había hecho la cofradía y obligar a que se hubieran llevado a cabo los propósitos de la hermandad (fiestas religiosas, entierros, actos de carácter benéfico y asistencial, etc.). En segundo lugar, evitar que los mayorales vells pudieran quedarse con alguna cantidad.

En cuanto a la relación de los cofrades con los mayorales, nadie podía entrometerse en la administración de los mayorales en la cofradía de Santa María de Valencia (1382), y si algún cofrade les decía palabras injuriosas en la cofradia de argenters (1418) debía pagar una multa de 50 sueldos barceloneses; si no pagaba tal cantidad se le condenaría a una pena de 50 días de prisión. En la cofradía de maestres d'obra de vila de Valencia (1418) también debían pagar 50 sueldos; además los mayorales

19 P. BONNASSIE, La organización del trabajo..., pp. 44-45.

20 Este sistema fue sustituido en Orihuela hacia el año 1417. J.A. BARRIO BARRIO, Gobierno municipal en Orihuela durante el reinado de Alfonso V, 1416-1458, Alicante, 1995, p. 175.

21 P. BONNASSIE, La organización del trabajo.., pp. 45-46. 
de esta cofradía podían requerir al portan veus del gobernador o a su lugarteniente para hacer cumplir la pena o para disminuirla. En el caso de que el cofrade no quisiera pagar debía ser expulsado sin posibilidad de retornar a la hermandad.

Tras los mayorales, el cargo en el que se observa una mayor regulación en las ordenanzas de este periodo es el de los andadores. Sus funciones se centraban en avisar a los cofrades para las reuniones del capítulo, sepulturas, aniversarios y otros menesteres que dependían de cada cofradía. Eran los únicos cargos que tenían un sueldo asignado para compensar sus labores. Pero estos rasgos generales no se desarrollan en todas las cofradías.

En cuanto a las relaciones de la cofradía con las instituciones de la Corona los propios mayorales podían encargarse de defender todo lo perteneciente a la cofradía, administrar los negocios y exigir al justícia o a su lochtinenth las penas cometidas por algunos cofrades, como sucede en las cofradías de las aldeas de Morella (1388), pero en otras hermandades también se podían constituir síndichs o procuradores que se encargasen de los negocios de la hermandad respetando los fueros y privilegios del reino y pudiendo intervenir en juicio o fuera de juicio.

\subsubsection{La reunión del capítulo}

El acto principal de la cofradía era el capítulo o reunión de todos los cofrades. La función del capítulo era administrar y tratar todos los negocios, hechos y obras de la almoina, así como tratar la posibilidad de que los cofrades se otorgasen nuevas ordenanzas. En el caso de la cofradía de maestres texidors (1392) se prohibia tratar temas ajenos a la misma, pero en las de pellers (1392) y lauradors del Quart de Campanar (1392) se permitía tratar otros asuntos, una vez finalizados los propios de las cofradías, siempre que fueran permitidos y honestos.

El capítulo solía realizarse o bien en alguna casa de religión —demostrando la influencia de las órdenes religiosas en el desarrollo de estas asociaciones-, o bien en la casa de la cofradía - con lo cual se puede incidir en la cada vez más compleja organización que necesitaban las cofradías que con el paso del tiempo iban adquiriendo distintas posesiones y bienes y ya no eran únicamente asociaciones de carácter religioso y benéfico. Pero en la mayoría de los casos las ordenanzas permitían a los cofrades elegir el lugar donde tendría lugar el capítulo.

Un dato sin duda importante era el hecho de que el monarca, que podría haber visto en esta concesión el germen de conflictos entre banderías, otorgase a las cofradías el derecho de reunirse en común para debatir sus asuntos. En la mayoría de las cofradías sus miembros tenían libertad para reunirse sin la presencia de oficiales reales, a no ser que los propios cofrades lo solicitaran, siempre que guardaran fidelidad al rey, $y$ a todos los servicios reales y vecinales y a los derechos reales.

La obligación de acudir al capítulo estaba regulado a través de una serie de ordenanzas en las que se castigaba con distintas penas las faltas por ausencia. La corrección fraterna es la base de esta cuestión. La mayor parte de las penas por no cumplir alguna de las ordenanzas o por no acudir al capítulo eran de cera para la luminaria. 


\subsection{Los deberes del cofrade}

\subsubsection{Cuotas y tasas}

Aparte de las cantidades que el nuevo cofrade debía pagar al entrar en la cofradía, semanal, mensual o anualmente se pagaba una cantidad distinta en cada almoina para mantener los negocios, las celebraciones religiosas y las labores asistenciales de la misma. La cofradía más cara era la de mercaders de Girona en Valencia (1368 y 1384) con 6 sueldos anuales y la que menos cuota anual exigía era la de texidors (1392) con 4 dineros anuales. En el caso de que estas cuotas no fueran suficientes para sostener los gastos de la cofradía las ordenanzas permitían a los mayorales establecer otras tasas excepcionales que debían ser justas y razonables.

\subsubsection{La comida de la cofradía y la «pietança»}

Una de las obligaciones más extendidas para los cofrades era la de asistir al menjar o comida de la cofradía y hacer la pietança - hacer caridad a los pobres. Se trataba en líneas generales de realizar una o varias comidas al año entre los miembros de la hermandad con el fin de que se conocieran y estrecharan lazos entre ellos; mientras que con la pietança venían a cumplir uno de los objetivos religiosos que fundamentaban su existencia como hermandad: la caridad. A este acto debía acudir cada cofrade obligatoriamente mientras que no hubiese una causa justificada que lo impidiese, de lo contrario era multado.

La comida de la cofradía no era únicamente lugar de reunión y fraternidad para los cofrades, también podía derivar en tumultos y conflictos ya fuera entre los miembros de la hermandad o como expresión de las aspiraciones de los oficios. Para controlar tan peligrosas actuaciones, las ordenanzas regulaban el número de ocasiones en que los cofrades podian reunirse. En la mayoría de las ordenanzas tan sólo se permitía una vez al año, una minoría de ellas podía menjar una o dos veces al año.

En cuanto a la pietança, no son muchas las cofradías que realizaban este tipo de actitudes caritativas hacia los sectores más humildes de la sociedad no pertenecientes a la propia asociación a pesar del ideal cristiano que las fundamentaba. Las cofradías que presentaban tales ordenanzas en la ciudad de Valencia eran menos del $18 \%$. Entre las cofradías del resto del reino nos encontramos también con un número bastante bajo de celebraciones relacionadas con la pietança (menos del $28 \%$ ). La actitud caritativa de estas hermandades estaba relacionada con la concepción que existía en la baja Edad Media alrededor de la imagen del pobre y de la pobreza, ya que a través de la caridad se alcanzaba el perdón de Dios ${ }^{22}$.

22 LLOP CATALA, «La predicación y las cofradias valencianas...”, p. 23. 
El tipo de religiosidad que impregnaba a las cofradías estudiadas se refleja en una serie de ordenanzas caracterizadas por establecer un control del comportamiento diario y la actitud moral de sus integrantes. Estos aspectos se referían tanto a cuestiones sexuales como lúdicas y económicas. En los capítulos de la cofradía de San Pedro (1370) aparecía la siguiente relación:

Ítem que si negú dels confrares de la dita almoyna haura muller e tendra amiga públicament o haura alguns mals uicis en si e per los majorals e prohomens de la dita almoyna seran amonestats e requestes III uegades que aquelles amigues o deudes dejen inquir e ab aquelles III ab altres en la dita forma no participar, e axí mateix dels dits confrares se deien castigar e aquells amonestats III vegades no vòlran estar a correcció dels dits majorals e prohomens que encontinent sien gitats de la dita almoyna ${ }^{23}$.

Ítem que si algú no sia reebut en aquesta confraria que sia en fama de esser ladre, ne homeyer, ne adultre, ne jugador, ne ques faça deui, ne sorter, ne que sia alcauot, ne ques despayll a ioch amagadament, ne en placa de que bega en tauernes publicament, ne que públicament sia hom que s'embriach, ne negú qui sia dauol fama ans si alguns d'aques seran en la dita confraria quant sia sabut que sia de tot en tot gitat de la dita confraria ${ }^{24}$.

El comportamiento vital y los hábitos de conducta en la Valencia bajomedieval intentaron ser reguladas a través de la literatura eclesiástica - San Vicente Ferrer y Eiximenis- por el propio interés del poder establecido ${ }^{25}$. Las cofradías se nutrieron de estas referencias y sus ordenanzas reflejaban el interés de los cofrades de alejarse de determinados comportamientos relacionados con el mundo marginado socialmente.

Casi todas las cofradías presentaban en sus ordenanzas sanciones de carácter general prohibiendo a los cofrades llevar una mala vida y tener malos vicios o no ser de buena fama vida y condición. Como asunto específico, una de las mayores preocupaciones de las cofradías era evitar que los cofrades jugasen, pues los juegos eran considerados causantes de reyertas, blasfemias, préstamos y enfrentamientos, en especial los dados, pues junto a los naipes era para el hombre medieval uno de los entretenimientos menos dignos. Estos juegos eran practicados por los marginados y estaban perseguidos y reprendidos por autoridades y moralistas ${ }^{26}$.

23 ACA, C, 918, fols. 108v-109r.

24 ACA, C, 918, fol. 110r.

25 R. NARBONA VIZCAÍNO, Pueblo, poder y sexo... p. 82.

26 J.A. BARRIO BARRIO, «Lo marginal y lo público en Orihuela a través de la acción punítiva del justicia criminal. 1416-1458", Anales de la Universidad de Alicante, Departamento de Historia Medieval, № 10, 1994-1995, p. 84. También hay que tener en cuenta las penas impuestas sobre las blasfemias en los fueros: Furs de València, Tomo I, Valencia, Imprenta de J. de Mey, edición facsímil, Valencia, 1990, Institut Valencià d’administració Pública. Fo. XCIII, Rúbrica XXII. 
Pero el tema más habitual en la reglamentación del comportamiento moral de los cofrades estaba relacionado con la sexualidad. La prohibición del adulterio aparecía de forma abundante entre los capítulos estudiados, tanto en referencia al cofrade que tuviera mujer legal y amante públicamente, como a la cofradesa que tuviera esposo y amante; lo cual puede ser una prueba de lo extendido que estaban estos comportamientos en el mundo bajomedieval valenciano. También se prohibía a los cofrades vivir en concubinato o practicar la prostitución, siendo expulsados tanto la fembra pública, como aquellos maridos cuyas mujeres practicaban la prostitución.

Si las cofradías se caracterizaban por alguna cuestión, aparte de por sus motivaciones religiosas, era por su intento de consolidar una imagen de riqueza y boato. Los gastos suntuarios abundaban en las ordenanzas mientras que únicamente en la cofradía de la Vera Creu de Xàtiva aparecía un capítulo en el que se vedaba a los cofrades llevar arneses de oro y de plata, vestidos con piedras preciosas o con perlas bajo pena de una libra de cera. Si alguno no quería pagar tal pena podía ser expulsado por el prior o los mayorales.

Las penas a los cofrades que no cumplían estas ordenanzas podian ser, dependiendo de la cofradía, tanto la imposición de una multa como la expulsión; pero en la mayoría de los casos se les permitía retractarse de su actitud. La fórmula más habitual, pero no la única, era amonestar al cofrade a través del guardia de los frailes menores, incidiendo de nuevo en el control moral que se ejercía a través de los conventos en las cofradías. Si el cofrade no obedecía eran los mayorales quienes debían amonestarlo a continuación, y en privado, hasta en tres ocasiones. En caso de que el cofrade se mantuviera en pecado, los mayorales debian poner el asunto en conocimiento del capítulo para que fuera expulsado «... a bon exempli d'aquells qui ben perseuarauent, a terror d'aquells qui semblant peccat volrien saiar defer... ${ }^{27}$. En otras ordenanzas estos temas quedaban exclusivamente como asuntos internos de la cofradía y no se recurría a elementos externos. Eran pốr tanto los mayorales y el capítulo quienes decidían.

Casi todos los capítulos estaban reglamentados de tal forma que si los cofrades los infringían debían pagar una multa a la almoina, al margen de aquellas que pudieran imponer las autoridades municipales si los actos cometidos iban contra el orden público y no sólo contra el orden confraternal. Y es que las cofradías no sólo imponían un régimen de conducta interna sino también un comportamiento ideal para con el resto de la sociedad. Tales penas presentaban un carácter privado. Podía tratarse de composiciones pecuniarias, la más habitual, o de multas en cera, una pena que nunca se aplicaba para los delitos públicos. El pago en cera era similar a la composición pecuniaria. El sentido de tal multa era hacer un servicio a la cofradía en uno de sus gastos más importantes, la luminaria para el culto religioso, con lo cual se expiaban las culpas y se compensaba la falta cometida al resto de hermanos. Se deriva una cuestión de utilidad a la hora de sustituir la composición pecuniaria por el pago en cera o aceite.

27 ACA, C, 479, fols. 167V-168r, Çabaters (1329). 
Estas multas recaían bajo la jurisdicción de los mayorales. Eran ellos quienes debían encargarse de vigilar el buen orden interno y de imponer las penas a los desobedientes. En ocasiones delegaban el cobro de las multas en los andadores y algunas penas, como la expulsión, debían imponerla de acuerdo con el resto de cofrades reunidos en capítulo.

Al ser estas penas de carácter privado, los cofrades podían negarse a pagarlas; de ahí que algunos capítulos daban facultad a los mayorales para solicitar la colaboración de los oficiales municipales para su aplicación, convirtiéndose de este modo en penas semipúblicas. La abundancia en la exposición de las penas que iban acompañadas al incumplimiento de los capítulos puede informarnos de un importante grado de infracción.

Vistas las numerosas penas establecidas en cera, así como con la compra de cirios para venerar la capilla del patrón bajo cuya advocación se encontraba la cofradía, podemos colegir que uno de los gastos más importantes de estas hermandades era sin duda la compra de velas, aceite, lanteas, etc. Esto permite suponer un importante desarrollo en el reino de Valencia de la industria de la cera. El componente religioso está presente al considerar que la luminaria es símbolo de la luz de Cristo y de su triunfo sobre la muerte. Se trata de una simbología expuesta por Santo Tomás que se expandió por toda Europa en este periodo ${ }^{28}$.

Con este punto podemos deducir también el amplio poder policial que poseían los mayorales y regidores de la cofradía para con el resto de cofrades, pues bajo su autoridad se imponian multas o se revocaban, se controlaba el cumplimiento de las ordenanzas y del espíritu de devoción cristiana que se quería transmitir a través de ellas. Como es lógico suponer, cualquier enfrentamiento entre cofrades era campo de actuación de los mayorales, en solitario o con el capítulo, cuya labor debía ser imponer la paz y expulsar para siempre a los que no obedecieran su mandato.

\subsection{Las posesiones de la cofradía}

Los estudios realizados hasta el momento acerca de las ordenanzas de las cofradías valencianas se han centrado exclusivamente en sus elementos religiosos y organizativos; pero a medida que tales ordenanzas se desarrollaban iban definiendo una serie de aspectos económicos, que permitían a algunas de estas asociaciones la posesión de bienes muebles, inmuebles y de carácter crediticio. Además, hay que tener en cuenta que el estudio de las cofradías a través de sus ordenanzas puede llevar a pensar que no había grandes diferencias entre las distintas hermandades debido a la homogeneidad de sus capítulos. Sin embargo, las desigualdades económicas y sociales son manifiestas como demuestra la diferencia de posesiones y el deseo de preeminencia social en actos como procesiones, entierros, celebraciones, etc.

Entre estas posesiones hay que incluir un variado espectro que iba desde elementos de claro corte suntuario a objetos cuya utilidad práctica se encontraba en relación

28 LLOP CATALÀ, «La predicación y las cofradías valencianas...» pp. 48-49. 
con las labores religiosas, benéficas y organizativas de las cofradías. Entre los bienes de carácter suntuario aparecían en determinadas cofradías distintos tipos de joyas, arneses de oro, plata, telas de seda, etc. Un apartado especial entre las ordenanzas lo ocupaban las posesiones de las cofradías relacionadas con los entierros de sus miembros. En la mayor parte de ellas se enumeraban paños ya fueran de oro, plata, seda, lana, lino o de terciopelo, forrados o no, cuya finalidad era cubrir el cuerpo del difunto; así como literas para trasladar el cuerpo en su entierro.

Entre los bienes inmuebles que aparecían en las ordenanzas de las cofradías valencianas podemos incluir las capillas y las casas o alberchs. Su posesión se hallaba relacionada con la compra de censales. Catorce — cerca del 19\%- fueron las cofradías que solicitaron licencia para construir una capilla en la que venerar al patrón de la hermandad.

La mayor parte de las capillas pertenecían a cofradías sitas en la ciudad de Valencia, presumiblemente con un mayor potencial económico que les permitiría el importante desembolso que suponía la construcción y el mantenimiento de las mismas. Algunas de ellas estaban relacionadas con la compra de censales para proveer a los religiosos que se encargaban de los oficios y para dotarlas con todos los bienes necesarios. El desarrollo económico de la ciudad de Valencia a fines del siglo XIV, la diversificación de los oficios, las inquietudes religiosas y el deseo de prestigio de las cofradías se reflejaban en la construcción de capillas bajo la invocación del patrón de tales hermandades.

De estas catorce cofradías, cinco de ellas solicitaron además una licencia para tener en posesión un alberch donde realizar los actos de la hermandad como reuniones entre mayorales y cofrades, capítulos, comidas, entierros, etc. Aparte de estas cinco cofradías con capilla y alberchs, nos encontramos con otras tres que solicitaron licencia para tener este segundo tipo de propiedades -en total cerca del $11 \%$. De esta cuestión se puede entresacar que algunas cofradías no sólo mantenían las motivaciones religiosas y benéficas que se hallaban entre los fines que sustentaban su origen, sino que evolucionaron - sobre todo a partir de 1392 - hacia un tipo de asociaciones cuyo potencial económico aumentó hasta obtener un patrimonio nada desdeñable; eso sí, dirigido hacia objetivos espirituales y asistenciales, pero también hacia el incremento del prestigio social y público.

Otra de las posesiones de las cofradías eran los cementerios, cuya construcción se puede rastrear a través de las autorizaciones aparecidas en las ordenanzas. Tres son los ejemplos más destacados. En primer lugar la cofradía de maestres d'obra de vila obtuvo licencia en el año 1415 para construir un cementerio propio. En segundo lugar observamos la cofradía de juponers i vanovers de Valencia en las ordenanzas del año 1418. Por último, en la también mencionada cofradía de San Amador que en año 1420 se unía a la de San Cristóbal aportando entre otras posesiones un cementerio entre las propiedades compradas a Bernat de Malferit. Esta tendencia hacia la posesión de un cementerio propio puede entenderse dentro del mismo espíritu confraternal que llevaba a los miembros de las cofradías a vivir en común y a enterrarse juntos como símbolo de unidad religiosa y social. 
En estrecha relación con la compra, dotación y posesión de capillas, casas, patios, huertos y alberchs se encontraba la compra de censales por parte de las cofradías. La mayor parte de las cofradías relacionadas con la compra de censales aparecieron en la ciudad de Valencia, pero no son las únicas. Así, la cofradía de la Vera Creu de Xàtiva recibía licencia en el año 1381 para que tanto el prior como los mayorales y los cofrades pudieran realizar firmas de censales, otorgar fadigas, recibir laudemios, firmar ventas, cambios y otras alienaciones de las posesiones censales de la cofradía y encargarse de todos los negocios que pertenecieran a la almoina. La cofradía de mercaders de Girona en Valencia (1391) podía poseer un alberch en la ciudad y censales siempre que no sobrepasasen los 15.000 sueldos reales de Valencia amortizados por los cofrades presentes y futuros. Si querían vender los censales concedidos podían comprar otros con laudemio y fadigas o utilizarlos en su totalidad o en parte para la compra del alberch. Así, algunas cofradías se convierten también en sociedades crediticias.

\subsection{Los capítulos religiosos}

\subsubsection{La advocación de las cofradías}

Casi todas las cofradías estudiadas se encontraban bajo la advocación de algún santo o de la Virgen, que eran mayoría. En el caso de Xàtiva nos encontramos además con una cofradía bajo advocación de la Vera Creu y otra con el nombre de la Santísima Trinidad, mientras que en la villa de Onda aparecía otra bajo advocación del Corazón de Cristo. Tanto la advocación a la Virgen como la de los santos solía provenir del nombre de la parroquia, monasterio o iglesia donde se asentaba la propia cofradía. Sin embargo, alrededor del $28 \%$ de las cofradías, todas ellas de oficio lógicamente, no presentaba en sus ordenanzas ninguna advocación concreta.

El culto a la advocación de la cofradía tenía diversas modalidades pero la más extendida era la de ofrecer una lantea o lámpara de aceite que ardiera en el altar del patrón tanto de noche como de día, para lo cual se utilizaba la pecunia recaudada semanalmente por los mayorales, el dinero de la almoina o las penas impuestas a los cofrades que no cumplieran las ordenanzas. La importancia de la luminaria dentro de la simbología cristiana se basa en la idea de la luz de Cristo y de su victoria sobre la muerte ${ }^{29}$, por este motivo las capillas confraternales y sus patronos se verán rodeados de cirios, candiles, lanteas y demás, al igual que las sepulturas de los cofrades, pues la muerte será entendida como un paso al reino de Dios.

La principal celebración religiosa era la fiesta de la advocación bajo cuyo nombre se hallaba la cofradía. La finalidad de tales actos era unir en hermandad a los cofrades bajo la concepción cristiana que movía a las cofradías. Las celebraciones no quedaban restringidas al día de la fiesta sino que se extendían también a las vísperas y al día posterior. Misas, vigilias y oraciones por los cofrades difuntos eran las labores

29 LLOP CATALÀ, «La predicación y las cofradías valencianas...», pp. 48-49. 
realizadas por los miembros de las cofradías. Cada una de ellas presentaba una serie de actos distintos.

El día siguiente de la fiesta los cofrades y cofradesas debían acudir a la iglesia para oír una misa de réquiem por los fieles difuntos que estuvieran sufriendo las penas del purgatorio en espera de la misericordia de Dios y por los cofrades que hubieran muerto en el último año. Las referencias al purgatorio aparecen en varias ocasiones en los documentos observados. Según Le Goff el surgimiento del purgatorio en el mundo cristiano medieval se produjo en el siglo XII y tuvo una gran expansión en el centuria siguiente. Tal desarrollo se relaciona con un cambio de mentalidad en el hombre medieval acerca de la vida terrena y la vida del más allá, y es reflejo de un cambio social debido a la aparición de la clase media. La creencia de que se podían redimir algunos pecados considerados "veniales" 0 "cotidianos" para alcanzar el cielo pasando una serie de pruebas se encontraba ya en los Padres de la Iglesia, pero no fue hasta el siglo XII que el purgatorio apareció como un lugar definido entre el cielo y el infierno ${ }^{30}$. Como afirma Le Goff, y podemos observar en la documentación, la creencia en la intervención de los vivos en favor de los difuntos suponía una interconexión entre este mundo y el más allá, al tiempo que permitía una mayor unión entre familias y comunidades, y el aumento de la influencia espiritual y económica de la iglesia ${ }^{31}$.

En este sentido, uno de los actos que más importancia se le daba en las cofradías era la celebración de un aniversario por las almas de los cofrades difuntos el día después de la fiesta de la advocación. En él se realizaban misas de réquiem, se rezaban las oraciones del Padrenuestro y el Avemaría o se recitaba los salmos penitenciales con el fin de obtener para los difuntos la salvación eterna y mitigar su paso por el purgatorio. Como la propia fiesta de la advocación, en tal celebración se producía una mezcla de sentimientos religiosos con el deseo de potenciar una imagen suntuosa de la cofradía que permitiera el reconocimiento social y prestigiara a la hermandad.

Por otra parte, destaca también el escaso interés de los capítulos por obligar a los cofrades a acudir a la celebración de la misa y a recibir los sacramentos, pues tan sólo se imponía para fechas concretas. Esta actitud se debía a la limitada inclinación existente en la religiosidad popular de superarse devocionalmente; el único objetivo de los cofrades era el de cumplir con lo establecido ${ }^{32}$.

\subsubsection{El entierro de los cofrades}

Cubrir las necesidades espirituales y vitales del hombre medieval llevó a las cofradías a desarrollar uno de los aspectos más importantes de la existencia de sus miembros, es decir, la muerte y el tránsito hacia la otra vida. Acompañar al cofrade en su última hora, rezar por el bienestar de su alma para que Dios lo acogiera entre los suyos, llevar a cabo el traslado de cofrades difuntos desde otras villas o ciudades hasta

30 Jacques LE GOFF, El nacimiento del Purgatorio, Madrid, 1985, pp. 9-17.

31 J. LE GOFF, El nacimiento.., p. 22.

32 LLOP CATALÀ, “La predicación y las cofradías valencianas...», p. 52. 
el lugar donde debía ser enterrado, extender los servicios de la hermandad a los familiares de los cofrades y solicitar permisos para tener literas y paños que permitieran el traslado del cadáver, son algunas de las cuestiones más importantes entre las ordenanzas relacionadas con el ceremonial y la simbología de la muerte.

En las ordenanzas se regulaba la obligación de acudir a los sepelios ante el llamamiento de mayorales o de los andadores, así como el número y el peso de los cirios, las vestimentas de los cofrades y la forma de acompañar al difunto. El número de oraciones que regulaban las ordenanzas para que Jesucristo perdonara los pecados cometidos en vida y que el cofrade difunto entrara en el reino de Dios o viera disminuidas las penalidades del purgatorio presentaba algunas variantes de una a otra cofradía, aunque en todas quedaban a la buena voluntad del cofrade. Las oraciones solían ser la del Padrenuestro o el Avemaría, pero una y otra podían ser sustituidas por los salmos penitenciales o por el pago de una misa.

Los servicios dedicados a los cofrades difuntos no se reducían a los integrantes de tales hermandades sino que se extendían también a los miembros de sus familias o en algunas ocasiones a cuantos vivieran bajo su techo. De esta forma el carácter protector en lo espiritual de las cofradías daba cobijo a la célula social más básica de este periodo, la familia. Las mujeres, los hijos, los padres del cofrade y también los mensajeros, los compañeros, los macips o los esclavos recibían, en algunas ocasiones, los beneficios de la almoina. Las cofradías serían, según Heers, grupos familiares artificiales integrados tanto por miembros de una familia unida por lazos de consanguinidad como por cuantas personas quisieran vivir en hermandad a partir de unos lazos vecinales, económicos y religiosos; en este sentido hay que tener en cuenta para la Edad Media la presencia de familias de carácter extenso relacionadas con los linajes nobiliarios, cuyo número superaba a la simple familia conyuga ${ }^{33}$. Las familias a partir de las cuales se formarían las cofradías estarían compuestas por los cónyuges, los hijos e hijas y, en ocasiones, los padres y hermanos de los cónyuges; en el caso de las condiciones económicas lo permitieran, también aparecerían domésticos y esclavos.

En definitiva, los ritos sobre la muerte expuestos aquí pueden presentarse como costumbres consoladoras que trataban de personalizar la muerte en tiempos normales y que se interrumpían en tiempos de peste ${ }^{34}$. El hombre medio medieval quería hacer comprensible y accesible la muerte, «normalizándola» a través de determinados actos que se repetían una y otra vez.

\subsection{Los capítulos benéfico-asistenciales}

La cofradía debe ser entendida, entre otros aspectos, como un marco de ayudas mutuas tanto de carácter terreno como espiritual, pero restringido a los propios miembros de tales asociaciones y, en algunos casos, como servicio a la sociedad circun-

33 Jacques HEERS, El clan familiar en la Edad Media, Barcelona, 1978, p. 20.

34 J. DELUMEAU, El miedo en occidente, Madrid, 1989, pp. 181. 
dante, en especial a los pobres y marginados. Pero incluso estas labores no son el fundamento de su fundación sino más bien el aglutinante de las distintas aspiraciones que dividian a los maestros y los macips de los oficios.

\subsubsection{El cuidado de los enfermos}

El aspecto más común a todas las cofradías es el acompañamiento del cofrade enfermo a lo largo de su enfermedad por parte de sus hermanos cofrades. Para que esta labor se realizara correctamente los mayorales se encargaban de ordenar a algunos cofrades que visitaran y velaran al enfermo. El número de cofrades que se encargaban de acompañar al enfermo variaba de una a otra cofradía, pudiendo ser de dos o más hermanos dependiendo de la decisión de los mayorales. Los cofrades se iban rotando hasta que el enfermo sanara o muriera. En algunos casos los cofrades sólo debían velar al enfermo si éste no tenía parientes o amigos que lo hicieran o si los compañeros de la casa no podían trabajar de día y velarlo de noche.

Pero el acompañamiento al cofrade enfermo en las horas en que podía abandonar este mundo no era el único deber de la cofradía hacia sus miembros para darle consuelo cristiano y fraternal. Sufragar las necesidades materiales ante la imposibilidad de trabajar también estaba cubierto por los capítulos. Para ello se dedicaba la cuota semanal que pagaban los cofrades al tiempo que costeaban los enterramientos y sostenían a los cofrades pobres. Pero la ayuda más habitual era la de proveer con alimentemos, vestidos o dinero a los cofrades enfermos que no pudieran ejercer su labor. En algunas cofradías sólo se atendía a aquellos cofrades cuya enfermedad no fuera por ninguna herida inducida por el maligno sino por la verga de Deu. De este modo se negaba la ayuda a aquellos cofrades que hubieran sido heridos en reyertas o en peleas. El orden y la paz social eran necesarias para el desarrollo económico, pero los propios oficios eran a su vez fuente de conflictos para defender sus intereses tanto de oficio, como familiares, vecinales o aquellos que los vinculaban a bandos nobiliarios ${ }^{35}$.

\subsubsection{Los cofrades caídos en pobreza}

Estas ordenanzas son una muestra tanto de la existencia de diferencias de riqueza dentro de las propias cofradías como de la movilidad económica a la que estaban expuestos sus miembros.

Entre los beneficios de carácter económico y asistencial que aportaban las cofradías a sus miembros encontramos en primer lugar las ayudas a los difuntos que no podían costearse un entierro digno dentro de las concepciones y los usos de la época. En varias cofradías se especificaba claramente una ayuda a aquellos cofrades que, sin estar enfermos, hubieran caído en pobreza o no pudieran sostenerse por sí mismos, siempre y cuando esta situación no fuera culpa del propio cofrade.

35 R. NARBONA VIZCAÍNO, Malhechores, violencia y justicia..., pp. 105-108. 
Al ser el reino de Valencia un territorio fronterizo que sufrió las consecuencias de la guerra con Castilla y en contacto también con el mundo musulmán, los conflictos derivados de estas circunstancias llevaron a las cofradías valencianas a solicitar licencias para ayudar y rescatar a aquellos cofrades que per sos pecats o per desastre cayeran en cautividad.

Para una fecha posterior en relación con el periodo estudiado aquí -siglos XVI y XVII-, Bennassar señala la costa del levante español como una de las más peligrosas por el acecho de los corsarios norteafricanos y que las actividades profesionales más expuestas eran las de pescadores y marinos ${ }^{36}$, pero para estos siglos también habría que tener en cuenta la presencia en la península del reino musulmán de Granada.

\subsubsection{La asistencia a los pobres de la ciudad}

Aparte de los actos de beneficencia hacia los miembros más desfavorecidos de las hermandades, las cofradías enfocaban también la caridad hacia los pobres y marginados que no pertenecieran a estas asociaciones. El concepto de pobreza existente en el mundo occidental alrededor de la Baja Edad Media se ve reflejado en las cofradías. La existencia de necesitados permitía a las cofradías llevar a cabo actos de caridad para alcanzar el perdón por los pecados cometidos, pero debía ser una caridad oculta, sin ostentación y por amor a Dios. Aún así se trataba de una caridad interesada, pues gracias a ella se lograba la salvación eterna ${ }^{37}$. Además, en las actitudes y en las ordenanzas de las cofradías se observa un cambio en el modo de pensar, pues no todos los pobres recibían las ayudas de estas hermandades, sólo los pobres vergonzantes podían alcanzar esta caridad. En relación con el desarrollo de una mentalidad de corte precapitalista, comienza a aparecer una nueva imagen de la pobreza que no tiene en cuenta los cambios de la fortuna o a la providencia divina y que considera al pobre como un ladrón o un perezoso, de ahí que empiece a hablarse de falsos pobres ${ }^{38}$.

\subsection{Las ordenanzas de carácter gremial}

El estudio de las ordenanzas de las cofradías permite observar la evolución que experimentaron algunas de estas hermandades a lo largo del tiempo, desde unas asociaciones de claro carácter benéfico y religioso cuyo objetivo real era el de servir como base institucional al desarrollo de los oficios, hasta convertirse en baluartes de control de esos mismos oficios.

36 Bartolomé y Lucile BENNASSAR, Los cristianos de Alá, Madrid, 1989, p. 169.

37 M. LLOP CATALÀ, «La predicación y las cofradías valencianas...», Pp. 23-26.

38 R. NARBONA VIZCAÍNO, Malhechores, violencia y justicia..., p. 131. 
El mundo artesanal en el periodo que va desde los inicios del siglo XIV hasta mediados del siglo XV se caracterizó por la organización de los oficios a través de las cofradías. A partir del año 1392, con los privilegios otorgados por Juan I, se produjo la mayor eclosión de estas organizaciones confraternales mediante la aportación de nuevas ordenanzas a cofradías ya constituidas o la aparición de nuevas cofradías de oficio. A partir de esta fecha, además, los capítulos otorgados presentaron una serie de elementos cuya función se centró en regular los aspectos laborales de los oficios, aunque todavía no se podía realizar una identificación total entre oficio y cofradía, como sucederá posteriormente con los gremios, debido a la existencia en la cofradía de miembros no pertenecientes al oficio y de menestrales que no pertenecían obligatoriamente a la corporación para poder ejercer su labor.

Sin embargo, en algunas cofradías estudiadas aparecen varios capítulos en los que se puede observar claramente cómo empieza a organizase el oficio a través de las ordenanzas de la hermandad. Son las cofradías de pellers (1392), armers (1392) argenters (1392 y 1418), calaffats (1392), tinters del drap de la lana (1393 y 1417) juponers i vanovers (1418), maestres d'obra de vila (1418) y corregers (1443). La diferencia entre las corporaciones gremiales europeas de las valencianas radicará en que estas últimas deberán coexistir con las cofradías de oficio, recogiendo de ellas tanto los elementos caritativos como su organización interna, pero aportando un mayor interés en la defensa de sus intereses económicos y sus prácticas técnicas ${ }^{39}$.

\subsubsection{La regulación de los obradores}

En la cofradía de corregers se imponía que sus miembros debían cerrar el obrador y la tienda tanto el domingo como en las fiestas que mandara la iglesia; además debian tener la puerta de sus casas abiertas para que se viera que no trabajaban ni vendían sus mercancías y para no provocar escándalo en esos días, lo cual supondría un mal ejemplo para el resto de conciudadanos, pero sí podían vender sus mercancías con licencia de uno de los mayorales. El incumplimiento de este capítulo suponía un pena de 5 sueldos.

Teniendo en cuenta la gran cantidad de capítulos existentes acerca de la obligatoriedad de los cofrades de asistir a todos los actos de las cofradías (capítulos, entierros, pietanças, esponsales, asistencia a enfermos, etc.) y las distintas penas y multas - hasta llegar a la expulsión- sobre los cofrades infractores, el tiempo anual de trabajo aparecía reglamentada por la cofradía. De este modo, la cofradía de corregers manifestaba explícitamente el derecho de la hermandad a regular el trabajo de los cofrades, pues sus miembros estaban obligados bajo una serie de multas a acudir a las celebraciones religiosas y festivas que impusieran las hermandades.

Dentro de este aspecto de control del trabajo artesano por parte de las cofradías se podría incluir un elemento que aparecía en el privilegio concedido a los maestres

39 VV.AA. Oficios artesanales y comercio..., p. 154 
d'obra de vila en el año 1418. Ningún maestro ni usante del oficio debía quitarle el moço a otro compañero bajo una pena de 100 sueldos.

\subsubsection{La obligación de pertenecer a la cofradía}

Uno de los aspectos que caracterizaron el mundo gremial fue la prohibición de practicar un oficio determinado a aquellos artesanos que no pertenecieran al gremio. Los motivos para explicar tal imposición se centraban en la necesidad de impedir cualquier posible competencia ajena a los miembros de las corporaciones. En las ordenanzas otorgadas a las cofradías aquí estudiadas nos encontramos con varios capítulos relativos a este asunto, pero con alguna variante. En la cofradía de argenters se solicitaba al monarca, en las ordenanzas del año 1392, que todos los artesanos que practicaban dicho oficio debían colaborar con la cofradía a causa del escaso número de menestrales que trabajaban en tal labor y a que muchos de ellos se hallaban inscritos en otras hermandades, aunque no se les obligaba a pertenecer a la cofradía; el motivo de tal solicitud radicaba en que al ser tan pocos artesanos no podían hacer honor a los entierros de los plateros muertos, por lo que solicitaban que todos los practicantes de este oficio acudieran a los sepelios y colaboraran con la cofradia bajo pena de 5 sueldos.

En las ordenanzas otorgadas a esta misma cofradía en el año 1418 se utilizaba un argumento asistencial para justificar la obligación de pertenencia a la cofradía, pues eran muchas las personas miserables del oficio que recibían ayuda de la corporación y los actos de caridad que realizaba la cofradía, así que todos los menestrales que practicaran el oficio, joves incluidos, tenían que pagar las tasas cada año fueran o no miembros de la cofradía. Quien no quisiera pagar tales cantidades no podía usar el oficio. Además, si algún argenter que no hubiera nacido en la señoría del rey llegaba a la ciudad, debía presentarse antes a los mayorales y hacer juramento de servir los capítulos, pagando primero 20 sueldos para la almoina de la cofradía. Ningún cofrade de cualquier ley, estamento o condición debía dar trabajo a tales argenters extranjeros hasta que recibiera el certificado por los mayorales y pagara los 20 sueldos; quien contraviniera tal ordenanza pagaría una pena de 20 sueldos a no ser que el nuevo argenter hubiera pagado ya 10 sueldos a la caja. Por último, ningún argenters podía usar de su oficio hasta que hubiera jurado los capítulos bajo una pena de 5 sueldos barceloneses.

\subsubsection{El control de la calidad}

El control de la calidad de los productos artesanos se encaminaba a impedir fraudes y abusos por parte de las autoridades municipales, y dio lugar a la aparición de un cargo en los oficios, el de los veedors como concesión del rey Jaime I en el año 1270 , dándole al oficio personalidad jurídica y un sentido político ${ }^{40}$. El hecho de que

40 TRAMOYERES BLASCO, Instituciones gremiales. Su origen y su organización en Valencia, 1889, pp. 314-315. 
los veedores del oficio deban ser cofrades suponía un paso fundamental en la gremialización de algunas de estas corporaciones de origen religioso. Pero no es hasta el año 1392 que dicho cargo se nombra explícitamente en unas ordenanzas, concretamente en la formada por los armers de Valencia y posteriormente en la de tinters del drap de la lana (1393), dentro del grupo de capítulos otorgados por Juan l en su estancia en Valencia. Después hay que esperar hasta el año 1415 para que en las ordenanzas de la cofradía de maestres d'obra de vila se nombren a dos maestros como veedors.

Es sin embargo en las ordenanazas de las cofradías de juponers $i$ vanovers y en la de argenters (ambas de 1418) donde nos encontramos con una información más detallada sobre la función de los veedors. En la primera de ellas se informaba que los dos o los cuatro mayorales de la cofradía podían ser veedors del oficio para actuar como policía ante los posibles fraudes cometidos por los juboneros y colcheros y para dar consejo a los mayorales de la ciudad que juzgaran tales abusos. Además, las ordenanzas incidían de forma exhaustiva que los veedores debían ser del oficio de juponers i vanovers y de ningún otro oficio.

Junto a la referencia anteriormente comentada acerca de la calidad del trabajo artesano también aparecía el cargo de veedor en la cofradía de argenters de Valencia (1418). En ella los mayorales de los argenters tenían dos compañeros de oficio para ayudarles a reconocer los obradores, cambres y otros lugares donde se trabajara el oro y la plata. Las ordenanzas les permitían llevar a cabo las inspecciones las veces que quisieran. En caso de recibir ofensas verbales e insultos de algún menestral, éste pagaría una pena de 100 sueldos; si no podía pagar dicha multa debía estar 20 días en la prisión. Además, los mayorales debían ser creídos siempre y si algún argenter era requerido para acompañarles en el reconocimiento debía hacerlo bajo pena de 5 sueldos.

Son las ordenanzas de esta cofradía y en las de este mismo año donde aparece por primera y única vez en este periodo un capítulo referente a la reglamentación técnica del oficio en relación con la calidad de su mercancías. Así, se prohibía colocar dobles piedras de vidrio o de cristal engastadas en oro para hacerlas pasar por diamante. El cofrade que infringiera esta reglamentación debía pagar cada vez 50 sueldos, de los que una tercera parte iba a parar al justicia de su jurisdicción, otra para el acusador y la otra para la caja de la cofradía. La obra fraudulenta debía ser destruida por los mayorales.

\subsubsection{Infieles, judios y esclavos}

En estrecha relación con la mentalidad de reconquista y de exclusión de las minorías religiosas aparecen varios capítulos en los que se prohibía la enseñanza de los oficios a los infieles. Por otro lado, la presencia de esclavos era un fenómeno generalizado en la agricultura, en la artesanía y en el servicio doméstico, pues Valencia era un centro de trata de esclavos con Oriente ${ }^{41}$.

41 La mayoría eran se raza blanca, sobre todo musulmanes, pero también cristianos (griegos, búlgaros, tártaros...); entre los poseedores de este bien tan cotizado había carpinteros, panaderos, mercaderes, artesanos del textil, etc. J. HINOJOSA MONTALVO, «La sociedad valenciana en el siglo XIV». Nuestra Histotia, Vol. III, Valencia, 1980, p. 160. 
En la cofradía de argenters (1418) se justificaba las limitaciones para esquivar fraudes, por lo que los menestrales debían ser personas leales y naturales al rey, prohibiendo que se enseñara el oficio a ningún judío, musulmán libre o esclavo, ni de cualquier nación sometida a esclavitud. Quien no cumpliera la normativa debía pagar 10 libras y expulsar de su obrador al infiel. Entre los extranjeros que sí podían tener en su obrador se nombraban a sardos y griegos por ser cristianos e hijos de catalanes. Tampoco los esclavos podían tener obra de oro ni cap de taula de plata en la ciudad, quien contraviniera el capítulo debía pagar una multa de 100 sueldos.

\subsubsection{El acceso a la maestría}

Un asunto que ha provocado discusión en la historiografía ha sido el acceso a la maestría en relación a si los hijos de los maestros tenían mayores facilidades a la hora de convertirse en maestros, o acerca de las dificultades del examen el pago de unas tasas inferiores si se era hijo de maestros, etc.

En las cofradías aquí estudiadas se observan muy escasas menciones al pago de tasas 0 al cumplimiento de exámenes para acceder a la maestría. En la cofradía de argenters (1418) sólo se exigía a los macips que hubieran nacido en la señoría del rey para poder obrar por sí mismos y que pagaran 10 sueldos para la almoina. El argenter que le diera obra antes de pagar los 10 sueldos debía pagar una multa de la misma cantidad. En la cofradía de maestres d'obra de vila no podía ser maestro nadie que no hubiera trabajado con otro maestro por espacio de cuatro años y que no hubiera sido examinado después; pero sólo se le concedía la licencia si superaba el examen. Cada vez que se contraviniera este capítulo debía pagarse una pena de 100 sueldos, la mitad para el rey y la otra mitad para el oficio. Los mayorales podían requerir al gobernador o a su lochtinent para que la pena fuera pagada o para que fuera rebajada. Sin embargo, en tales ordenanzas no se mencionaba cual era la prueba que debía pasar el oficial ni quienes se encargaban de examinarlo.

En la cofradía de corregers (1443) se establecía el mismo periodo de oficializazgo y la necesidad de pasar un examen para abrir el obrador. Este examen se realizaría ante cuatro prohomens corregers elegidos por los mayorales. El examinado debía pagar a la almoina 22 sueldos.

El hecho de que fueran las cofradías quienes exigieran experiencia como macip a la orden de un maestro durante algunos años y la imposición de una tasa para poder tener obrador propio junto con las prohibiciones de enseñar a infieles o cautivos, la aparición del cargo de veedor o la obligación a pertenecer a la cofradía para poder ejercer tal oficio supuso un cambio y una evolución hacia el control del oficio por parte de alguna de estas asociaciones, mientras que otras, la mayoría, no solicitaron ningún tipo de licencias para ejercer tal control a lo largo de este siglo y medio, y permanecieron como asociaciones religiosas y asistenciales a partir de las cuales se organizaban los oficios. 


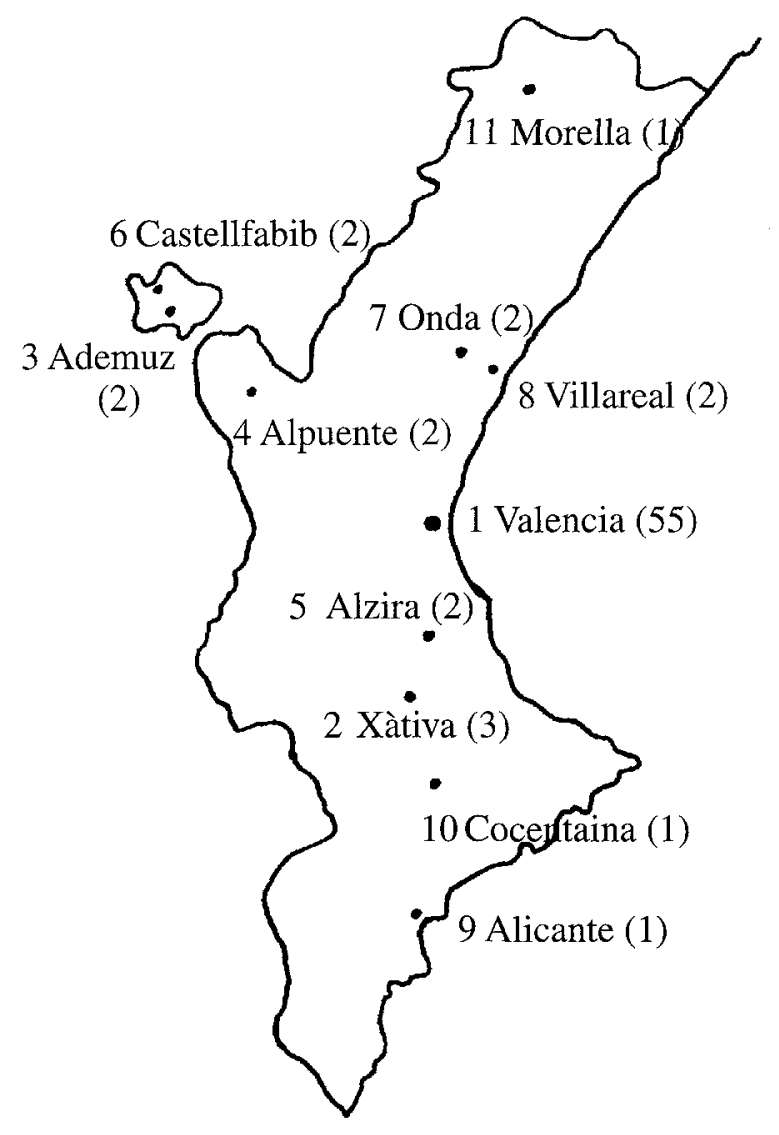

\section{CONCLUSIONES}

Las ordenanzas otorgadas a las cofradías valencianas bajomedievales presentan una complejidad que es el resultado tanto de las necesidades que venían a cubrir como de la sociedad en la que aparecieron.

Tanto las cofradías religiosas como las de oficio se presentaban, en su mayoría, como organizaciones religiosas o benéficas centradas en el culto, la caridad, la ayuda a cautivos y enfermos, el entierro de cofrades, etc.

En cuanto a los capítulos que regulaban la organización interna de las cofradías, eran sin duda los más variados y extensos en los privilegios otorgados por los distintos monarcas. En primer lugar hay que tener en cuenta que las cofradías se presentaban como asociaciones abiertas para todo tipo de gentes, ya fueran hombres o mujeres; con esto, las hermandades pretendían dar una imagen de apertura social. Pero en realidad estas asociaciones eran esencialmente de carácter restrictivo, ya que 
en ellas aparecian una serie de condiciones eliminatorias tanto pecuniarias, como morales y religiosas. Lo que suponía un freno a los marginados sociales y a las minorías religiosas.

Una vez regulado el acceso a las cofradías, las ordenanzas se encargaban de sentar las bases de su organización administrativa. En primer lugar destaca el carácter colegiado de dicha organización del que sobresalían una serie de cargos específicos: el prior, los mayorales, los andadores, los síndicos y los veedores.

El acto principal de la cofradía era la reunión de todos los cofrades en el capítulo. Su función era administrar y tratar todos los negocios de la almoina, así como tratar la posibilidad de que los cofrades se otorgasen nuevas ordenanzas, con lo cual tenían una posibilidad de mejorar y rectificar los capítulos que regulaban sus actividades para que no se convirtieran en estatutos inamovibles cuya funcionalidad estuviera limitada por el paso del tiempo.

Los estudios realizados hasta el momento acerca de las ordenanzas de las cofradías valencianas se han centrado exclusivamente en sus elementos religiosos y organizativos; pero a medida que tales ordenanzas se desarrollaban iban definiendo una serie de aspectos económicos, que permitían a algunas de estas asociaciones la posesión de bienes muebles, inmuebles y de carácter crediticio.

Aparte del elemento organizativo, tres fueron los ejes a partir de los cuales se conformaron los capítulos de las cofradías. El primer eje a tener en cuenta es el desarrollo del interés religioso y espiritual a partir de la predicación de las ordenes religiosas (franciscanos, dominicos y agustinos) y su asentamiento fundamentalmente urbano, pues no hay que olvidar que tres cuartas partes de las cofradías estudiadas aparecieron en la ciudad de Valencia. Los pilares básicos de la religiosidad practicada por las cofradías se centraban en tres aspectos: el culto a la advocación que daba nombre y contenido religioso a la cofradía, la participación de los cofrades en los oficios y en el culto divino, y el aparato ceremonial que rodeaba a la defunción y entierro de los cofrades.

El segundo eje sobre el que se centraron las cofradías fue de corte benéficoasistencial como respuesta a una sociedad que no podía cumplir con dichos aspectos. Se trataba fundamentalmente de una solidaridad restringida a los propios miembros de las cofradías. Sus actos de caridad hacia el exterior estaban marcados al mismo tiempo por el espíritu religioso que las motivaba como de cierto tono de ostentación social. Pero las cofradías no sólo presentaban este aspecto de ayuda en la tragedia sino que servían también de punto de apoyo para el hermanamiento y la devoción cristiana en actos como los capítulos, la caridad, la comida de las cofradías y los matrimonios de los miembros de tales hermandades o de sus familiares.

El tercer eje hace referencia a las cofradías de oficio. Estas fueron las que experimentaron una evolución más significativa, pues la autorización de tales asociaciones supuso en un primer momento un reconocimiento jurídico-institucional de los oficios a los que representaban. El carácter jerárquico del mundo artesanal se irá filtrando en estas hermandades, al igual que las pretensiones de monopolio corporativo. A su vez, las cofradías impregnarán los oficios del sentido religioso y caritativo que las motiva- 
ba. Los elementos gremiales destacarán de manera más nítida en las cofradías de oficio a partir de los últimos años del siglo XIV y tendrán un desarrollo más significativo en la centuria siguiente.

Las cofradías supusieron la aceptación y «normalización» del mundo artesanal en la sociedad del medioevo y permitieron la integración de los artesanos en tal sociedad. Del gran número de inmigrantes que se dirigió a la ciudad de Valencia a lo largo del siglo XIV sólo unos pocos lograron ser aceptados en ella y huyeron de la marginación ${ }^{42}$. Pertenecer a una cofradía permitía tal adaptación. Pero su importancia social no terminó ahí. El deseo de prestigio se traslucía a través de sus posesiones, de sus capítulos religiosos y benéficos, de su organización cada vez más desarrollada, del número de cirios con los que se daba culto al patrón, de sus estandartes, pendones y banderas, de los ritos y ceremonias con que se acompañaban a los difuntos a su último descanso, de las obras de caridad, etc.

La rivalidad entre unos oficios y otros, entre unas cofradías y otras no estuvo exenta de conflictos. Fue una rivalidad económica y social que derivó de una organización del trabajo basado en un régimen de privilegio, pues las ordenanzas fueron concedidas como reglamentos particulares a cada oficio, sin que existiera una síntesis legal común $^{43}$. La violencia desarrollada por los oficios estuvo más relacionada con las banderías nobiliarias -en cuanto a su dimensión política y social- que con la violencia espontánea de los marginados, pero son incluso "más importantes en número, crueldad y variedad que la de los nobles valencianos" $" 44$.

42 R. NARBONA VIZCAÍNO, Malhechores, violencia y justicia..., p. 59.

43 BONNASSIE, El trabajo en Barcelona..., p. 63.

44 R. NARBONA VIZCAÍNO, Malhechores, violencia y justicia..., p. 108. 